\title{
Comparison between Standard preoxygenation and Transnasal Humidified Rapid Insufflation Ventilatory Exchange (THRIVE) in Difficult Airway during Induction of Anaesthesia
}

\author{
Z Belamaric, D Nagore, JP Jimeno, A Bilbao, T Garth, K Plummer \\ Department of Perioperative Medicine, St. Bartholomew's Hospital, London, UK
}

\begin{abstract}
Background: Securing the airway can prove to be a challenge for the anaesthetist and may require use of different tools and change of strategy. In this phase it is pivotal to improve the oxygenation and prevent desaturation. We compared THRIVE and standard preoxygenation during induction of anaesthesia in patient with predicted difficult airways.

Method: 30 adult patients, undergoing elective surgery in whom the presence of difficult airway was known or strongly anticipated based on unfavourable predictors (BMI>35, decreased thyro-mental distance, limited mouth opening, limited neck extension, Mallampati score $\geq 3$ ) were randomised into two groups: 1) Standard 5 minutes pre-oxygenation $(100 \% \mathrm{FiO} 2)+$ mask ventilation between intubation attempts 2) THRIVE: 5 minutes preoxygenation with THRIVE (100\% $\mathrm{FiO} 2)$ at a rate of $60 \mathrm{l} / \mathrm{min}$ + continuous THRIVE until a definitive airway was secured. Induction was standardised for both groups and intubation performed by the same consultant anaesthetist.

Results: The 2 groups were similar in demographic parameters. Mean baseline $\mathrm{SpO} 2$ was $97.8 \%$ in both groups. The mean time to secure the airway was $161.9+/-49.6 \mathrm{sec}$ for THRIVE and $166.7+/-54.7 \mathrm{sec}$ for the standard group ( $p$ value $=0.80$ ). There was 1 adverse effect in THRIVE and 4 in standard group ( $p$ value $=0.24$ ). The mean number of laryngoscopy attempts was 1.73 in THRIVE and 2 in standard group ( $p$ value $=0.5$ ). The number of desaturation episodes was significantly different: no episodes for THRIVE vs. 4 episodes for the standard group ( $p$ value $=0.03$ ).
\end{abstract}

Primary endpoint

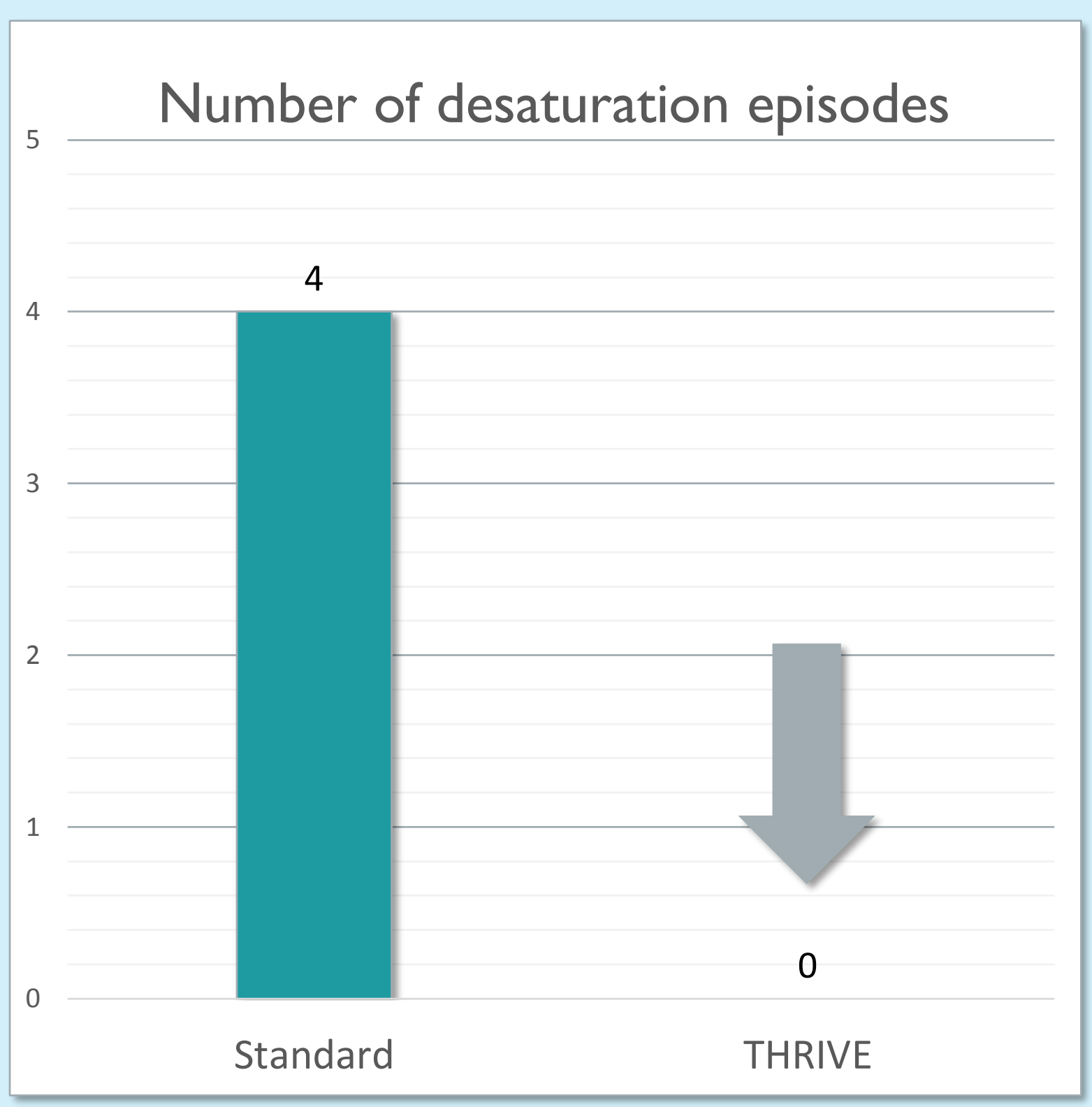

$P$ value $=0.03$

\section{Secondary endpoints}

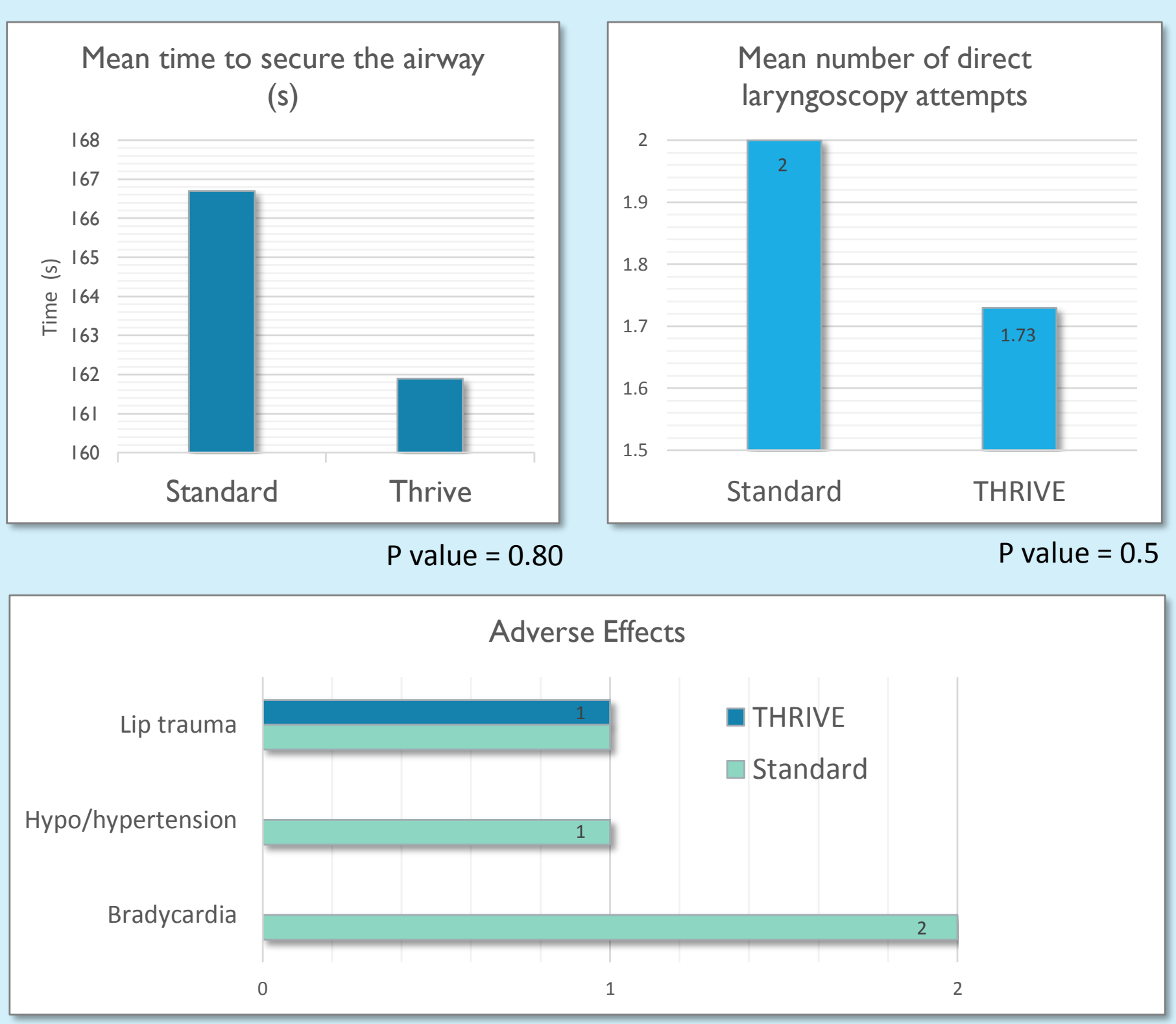

$P$ value $=0.24$

\section{Conclusion}

Although there was no statistically significant difference in the time or number of attempts to secure the airway or in the incidence of adverse effects, THRIVE significantly reduced the number of desaturation episodes. In our opinion THRIVE may prove to be an useful tool especially in cases of anticipated difficult intubation.

Baraka AS, Taha SK, Aouad MT, El-Khatib MF, Kawkabani NI. Preoxygenation: comparison of maximal breathing and tidal volume breathing techniques. Anesthesiology 1999; 91: 612-6.

- Baillard C, Fosse JP, Sebbane M, et al. Noninvasive ventilation improves preoxygenation before intubation of hypoxic patients. American Journal of Respiratory and Critical Care Medicine 2006; 174: 171-7.

- Dixon BJ, Dixon JB, Carden JR, et al. Preoxygenation is more effective in the 25 degrees head-up position than in the supine position in severely obese patients: a randomized controlled study. Anesthesiology 2005; 102: 1110-5.

- Griesdale DEG, Bosma TL, Kurth T, Isac G, Chittock DR. Complications of endotracheal intubation in the critically ill. Intensive Care Medicine 2008; 34: 1835-4 